\title{
Studi Pelokalan dan Pemancanegaraan dalam Penerjemahan Istilah Budaya dari Bahasa Indonesia ke dalam Bahasa Inggris (Kajian Linguistik Terjemahan Pada Novel Entrok Karya Okky Madasari)
}

\author{
Tri Pujiati \\ Program Studi sastra Indonesia, Universitas Pamulang \\ tpujiati.unpam@gmail.com
}

\begin{abstract}
Abstrak
Penelitian ini akan mengkaji terjemahan istilah budaya pada novel Entrok karya Okky Madasari. Penelitian ini bertujuan: (1) Untuk menemukan dan mendeskripsikan pelokalan dan pemancanegaraan pada novel Entrok karya Okky Madasari; (2) Untuk menemukan dan mendeskripsikan prosedur penerjemahan kata budaya dari bahasa Inggris ke dalam bahasa Indonesia pada novel Entrok karya Okky Madasari; (3) Untuk menemukan dan mendeskripsikan tingkat kesepadanan terjemahan kata budaya dari bahasa Indonesia ke dalam bahasa Inggris pada novel Entrok karya Okky Madasari. Penelitian ini menggunakan pendekatan kualitatif dengan metode analisis isi. Berdasarkan penelitian, ditemukan bahwa (1) terdapat pelokalan sebanyak 25 data dan pemancanegaraan sebanyak 11 data dalam terjemahan novel Entrok. Pelokalan terjadi karena penerjemah ingin mempertahankan terjemahan dalam teks sasaran sehingga menyesuaikan dengan teks sumber. Adapun pemancanegaraan terjadi karena penerjemah ingin mempertahankan budaya sumber pada saat menerjemahkan ke dalam teks sasaran; (2) prosedur penerjemahan yang ditemukan pada pelokalan adalah harfiah $60 \%$, pergeseran $28 \%$, kesepadanan budaya $8 \%$, dan catatan kaki $4 \%$ sedangkan pada pemancanegaraan adalah catatan kaki sebesar 54,5\%, transferensi 27,2\%, dan harfiah 18,2\%; (3) pada hasil terjemahan, terlihat bahwa terdapat dua kesepadanan yang digunakan dalam terjemahan, yaitu kesepadanan dinamis dan kesepadanan formal. Hasil penelitian ini diharapkan mampu memberikan pengetahuan tentang cara menerjemahkan kalimat kata budaya bahasa Inggris ke dalam bahasa Indonesia dengan baik dan benar sesuai dengan budaya dari bahasa sumber dan bahasa target.
\end{abstract}

Kata kunci: pelokalan dan pemancanegaraan, penerjemahan, novel.

\section{A. Pendahuluan}

Penerjemahan sebagai upaya pengalihan pesan dari bahasa sumber ke dalam bahasa sasaran banyak mengalami perkembangan. Fakta empiris menunjukkan bahwa penerjemahan seagai salah satu disiplin ilmu linguistik terapan mampu memberikan kontribusi bagi dunia pendidikan sebagai upaya untuk mentransfer bahasa sumber ke dalam bahasa sasaran, misalnya dari bahasa Inggris ke dalam bahasa Indonesia ataupun sebaliknya. Tidak hanya bagi dunia akademik, penerjemahan mampu menjadi jembatan penghubung bagi penulis karya satra yang ingin mempersembahkan karya sastranya ke dalam bahasa asing. Penerjemahan bisa menjadi solusi bagi para sastrawan untuk bisa memperkenalkan karya 
sastranya di mata internasional. Fakta lapangan menunjukkan bahwa masih jarang karya sastra Indonesia yang diterjemahkan ke dalam bahasa asing. Namun, seiring perkembangan zaman dan kemajuan ilmu pengetahuan dan teknologi maka karya sastra mulai banyak berkembang dan diterjemahkan ke dalam bahasa Inggris, misalnya novel Laskar Pelangi karya Andrea Hirata, novel Entrok karya Okky Madasari, dan lain sebagainya.

Proses penerjemahan karya sastra khususnya teks yang terdapat pada novel memiliki tingkat kesulitan yang berbeda dengan teks bahasa ilmiah karena di dalam pengalihan teks ini membutuhkan pemahaman yang mendalam terkait dengan isi cerita, dialog antar tokoh, latar, serta mood yang diciptakan oleh penulis asli harus mampu diterjemahkan secara baik oleh penerjemah. Haque (2012: 97) mengatakan bahwa penerjemahan karya sastra merupakan proses pengalihan pesan dari satu bahasa yang ditulis ulang ke dalam bahasa-bahasa yang lain. Hal ini berbeda dengan apa yang diutarakan oleh Nord (1997: 80-84) yang mengatakan bahwa menerjemahkan karya sastra bukan hanya mengalihkan pesan atau mencari padanan dari bahasa sumber ke dalam bahasa sasaran, tetapi menerjemahkan ide dan tujuan pengarang sehingga pesan asli dan tujuan penulisan pesan itu sendiri sampai kepada pembaca. Misalnya, pada saat di dalam novel asli penulis membuat cerita yang lucu atau sedih, maka pembaca harus mampu membuat pesan tersebut sampai kepada pembaca sesuai dengan situasi dari novel aslinya sehingga novel terjemahan bisa dirasakan oleh pembaca sebagai sebuah karya baru yang tidak jauh berbeda dengan teks aslinya. Hal ini selaras dengan apa yang diungkapkan oleh Hoed dalam Hartono (2011: 62) yang mengatakan bahwa menerjemahkan sebuah novel hendaknya seperti mendongengkan kembali isi ceritanya kepada orang lain sehingga hasil terjemahannya itu tidak tampak sebagai terjemahan, tetapi sebuah dongeng yang alamiah dan enak dibaca.

Problematika di atas menjadi salah satu masalah yang banyak dialami dalam proses penerjemahan. Selain itu, permasalahan pokok yang terdapat pada penerjemahan novel dari bahasa Indonesia ke dalam bahasa Inggris adalah permasalahan budaya. Perbedaan budaya sering membuat penerjemah kesulitan untuk mencari padanan yang tepat untuk mentransfer bahasa sumber ke dalam bahasa sasaran. Sudana (2014: 437) mengatakan bahwa kendala budaya ini berpengaruh besar dalam penerjemahan karena tidak semua istilah ada padanannya dalam budaya lain. Torop (2002: 593) mengungkapkan bahwa teori tentang budaya yang terdapat pada area tertentu merupakan suatu konsep yang menyeluruh terhadap budaya tersebut. Albakry (2004: 5) mengatakan bahwa terjemahan karya sastra merupakan piranti seni yang mengandung isu-isu budaya sehingga menerjemahkan karya sastra tersebut 
tidak mudah, penerjemah harus mendalami budaya sumber terlebih dahulu sebelum mengalihkannya ke dalam bahasa sasaran.

Novel sebagai salah satu bentuk karya sastra disuguhkan melalui narasi dan dialog. Dialog novel dipilih oleh penulis novel agar cerita tidak monoton dan lebih menarik hati pembaca. Pada saat menyampaikan cerita dalam bentuk dialog, pengarang terkadang menggunakan implikatur-implikatur yang maknanya tidak bisa dipahami secara tersurat, namun perlu pemahaman yang mendalam terkait tuturan yang ada di dalam dialog tersebut. Pada proses penerjemahan, penerjemah harus mampu memahami implikatur-implikatur tersebut dan mencari padanan yang tepat sehingga maksud yang ingin disampaikan oleh pembaca tersampaikan dengan baik. Newmark (1988: 170) mengatakan bahwa ungkapanungkapan yang ada pada dialog novel seringkali berupa implikatur-implikatur yang sarat makna berdasarkan konteks sosiokultural pengguna bahasa sumber sehingga penerjemah harus mampu mencari padanannya sesuai dengan konteks sosiobudaya pengguna bahasa sasaran. Pada saat pengalihan pesan dalam bentuk dialog, penerjemah sering dihadapkan pada ungkapan implikatur yang diucapkan oleh tokoh dalam novel yang maknanya perlu dikaji dengan pendekatan sosial dan budaya yang berlaku pada bahasa sumber dan penerjemah harus bisa memahami kondisi sosial budaya yang terdapat pada bahasa sasaran sehingga pesan dalam bahasa sumber dapat tersampaikan secara tepat di dalam bahasa sasaran tanpa mengesampingkan budaya yang terdapat pada bahasa sumber.

Berdasarkan pemaparan-pemaparan pada paragraf sebelumnya, dapat diidentifikasi permasalahan terkait penerjemahan novel dari bahasa Indonesia ke dalam bahasa Inggris yang sarat akan budaya yang berbeda. Saya mengerucutkan permasalahan dalam penelitian sebagai upaya mencari solusi penerjemahan novel yang berkualitas sehingga akan banyak lagi karya-karya novel Indonesia yang bisa diakui di dunia internasional. Penelitian ini mengacu pada penerjemahan budaya dari Newmark (1998) yang mengatakan bahwa terdapat 5 kriteria budaya dalam penerjemahan, yaitu (1) Ekologi (2) Budaya materiil (3) Budaya sosial, misalnya jenis pekerjaan (4) Organisasi, tradisi, aktivitas, dan konsep (5) Kial atau bahasa tubuh dan kebiasaan. Pada setiap proses reproduksi, tentu ada ideologi yang membayangi penerjemah dalam mengalihkan pesan dari bahasa sumber ke dalam bahasa sasaran. Basnett dan Levere dalam Venuti mengatakan bahwa ideologi adalah suatu prinsip yang dipercayai kebenarannya dalam suatu masyarakat, Hoed (2006: 83). Ideologi pemancanegaraan sering digunakan penerjemah dengan maksud agar pembaca diperkaya pengetahuannya dengan membaca sesuatu yang asing dan juga pemertahanan bahasa sumber. Namun, pandangan ini banyak dipertentangkan karena bertolak belakang dengan ideologi 
domestikasi atau pelokalan yang berusaha memperkenalkan salah satu aspek kebudayaan yang ada di dalam bahasa sasaran, Hoed (2006: 88).

Fakta empiris yang telah saya telusuri untuk mendukung kelayakan isu penelitian yang saya angkat, maka saya melakukan kajian terhadap penelitian-penelitian terdahulu sebagai rujukan dan upaya untuk mengisi rumpang terhadap gap dari penelitian sebelumnya. Penelitian terdahulu yang dilakukan oleh Zare Esmail , Behtash and Firoozkoohi Sepideh (2009); Yang, Wenfen (2010); Ayoub, Shaifta (2014); Ye, Hongwei. (2014); Siregar, T, Roswani dkk. (2015); Shahabi, Hassan \& Raheleh Rezaei Shams Abad (2016); dan Baawaidhan, Awadh (2016) menunjukkan bahwa permasalahan budaya sering menjadi masalah pokok bagi penerjemah sehingga ideologi pelokalan dan pemancanegaraan menjadi solusi utama dalam penerjemahan kata budaya.

Mengacu pada penelitian-penelitian terdahulu, maka dapat dilihat bahwa penelitian terdahulu tidak mengkaji secara mendalam terkait dengan aspek keakuratan, keberterimaan, dan keterbacaan teks terjemahan kata budaya ke dalam teks sasaran sehingga masih banyak rumpang yang belum diisi terkait dengan penerjemahan dan budaya. Pelokalan dan pemancanegaraan memang dipandang sebagai sebuah ideologi yang banyak dipertentangkan terutama pada penerjemahan istilah budaya pada teks bahasa Indonesia ke dalam bahasa Inggris khususnya teks sastra sehingga kualitas terjemahan dari novel tersebut perlu dievaluasi sebagai bentuk upaya perencanaan penerjemahan kata budaya yang berkualitas dan berterima pada bahasa sasaran.

Penelitian ini akan menggunakan objek kajian berupa novel Indonesia yang dialihbahasakan ke dalam bahasa Inggris. Novel yang akan dijadikan objek kajian adalah novel Entrok karya Okky Madasari yang diterbitkan oleh Gramedia Pustaka Utama pada tahun 2010. Novel ini layak untuk dijadikan objek kajian terjait dengan penerjemahan dan budaya karena beberapa alasan. Pertama, pada terjemahan novel, banyak ditemukan ideologi pelokalan dan pemancanegaraan pada penerjemahan kata budaya. Kedua, novel ini sarat akan budaya Indonesia sehingga pengkajian terhadap terjemahan kata budaya tersebut ke dalam bahasa Inggris akan menjadi jembatan untuk memperkenalkan budaya Indonesia, khususnya budaya masyarakat Jawa. Ketiga, banyak ditemukan pergeseran dalam penerjemahan istilah budaya dari teks bahasa Indonesia ke dalam bahasa Inggris yang memang memiliki budaya yang berbeda sehingga pergesaran tersebut sering dilakukan oleh penerjemah.

Membaca novel Entrok banyak menumbuhkan emosi, sedih, kesal, dan bahkan marah dengan kondisi yang terjadi pada tokoh utama. Dari judul yang diusung dalam novel, Entrok mampu membuat penasaran karena banyak pembaca yang masih belum mengetahui apa 
makna dibalik entrok, yang di dalam bahasa Jawa bermakna $\mathrm{BH}$ atau bra yang dipakai oleh wanita masa lampau untuk menutupi payudara mereka. Di balik judul yang disajikan, Okky ingin mengupas kehidupan wanita dan para penguasa pada zaman orde baru secara lugas dan jelas serta bahasa yang mudah dipahami. Pada akhirnya, novel ini mampu menjadi magnet bagi para peminat sastra dan menarik untuk diperkenalkan ke luar negeri melalui tulisan yang tentunya harus sesuai dengan pesan yang disampaikan oleh penulis asli. Pada tahun 2013, novel ini dialihbahasakan oleh Nurhayat Idriyatno Mohamed dengan judul yang berbeda dengan judul aslinya, yaitu The Years of the Voiceless sebagai padanan dari Entrok. Tampak sekali bahwa penerjemah mengalihkan makna tersirat yang terdapat pada keseluruhan novel dengan judul yang sangat berbeda dengan judul aslinya sehingga membuat pembaca penasaran.

\section{B. Metode Penelitian}

Penelitian ini akan menggunaan metode analisis isi dengan pendekatan kualitatif. Peneliti menggunakan pendekatan kualitatif karena dalam penelitian ini menghasilkan data deskriptif berupa kata-kata tertulis atau lisan dari orang-orang atau perilaku yang dapat diamati. Peneliti memilih analisis isi karena penelitian ini akan mengutamakan analisis teks yang terdapat di dalam dialog novel. Krippendroff mendefinisikan analisis isi sebagai ' $a$ research technique for making replicable and valid inferences from texts (or other meaningful matter) to the context of their use', analisis isi merupakan sebuah teknik untuk membuat tiruan dan kesimpulan valid dari teks (atau sesuatu hal yang bermakna) ke konteks penggunaannya, (Krippendroff: 18).

\section{Pembahasan}

\section{Pelokalan dalam Terjemahan Novel Entrok Karya Okky Madasari}

Dalam penerjemahan kata budaya, penggunaan ideology pelokalan sering dilakukan oleh penerjemah. Venuti dalam Hoed (2006: 14) mengatakan bahwa ideologi domestikasi (pelokalan) mengacu pada bahasa sasaran, yaitu bahwa terjemahan yang betul, berterima, dan baik adalah yang sesuai dengan cita rasa masyarakat bahasa sasaran.

Berikut ini temuan penelitian terkait dengan pelokalan dalam terjemahan novel Entrok Karya Okky Madasari.

Pelokalan dalam Terjemahan Novel Entrok

\begin{tabular}{|l|l|l|l|l|}
\hline $\begin{array}{l}\text { No } \\
\text { Urut } \\
\text { Data }\end{array}$ & TSu & Hal & TSa & $\begin{array}{l}\text { Hal } \\
\cdot\end{array}$ \\
\hline 001 & $\begin{array}{l}\text { Zaman sudah berubah, bu. } \\
\text { Semuanya sudah berbeda." }\end{array}$ & 13 & $\begin{array}{l}\text { "The times have changed, mom. } \\
\text { Everything is different." }\end{array}$ & 11 \\
\hline
\end{tabular}




\begin{tabular}{|c|c|c|c|c|}
\hline 002 & $\begin{array}{l}\text { "Takgendong...cucuku...takgendo } \\
\text { ng...cucuku" }\end{array}$ & 14 & $\begin{array}{l}\text { "I'll carry you....my } \\
\text { grandchildren" }\end{array}$ & 12 \\
\hline 003 & $\begin{array}{l}\text { "Takgendong...cucuku...takgendo } \\
\text { ng...ke mana-mana!"”" }\end{array}$ & 14 & $\begin{array}{l}\text { "I'll carry you....my } \\
\text { grandchildren ...I'll carry you } \\
\text {...everywhere" }\end{array}$ & 13 \\
\hline 004 & Oh...Ibu" & 14 & "Oh...Mother" & 13 \\
\hline 005 & $\begin{array}{l}\text { Simbok bilang aku sudah } \\
\text { mringkili. } \\
\text { Payudara yang mulai tumbuh }\end{array}$ & 16 & $\begin{array}{l}\text { "Simbok told me that I was } \\
\text { growing up }\end{array}$ & 13 \\
\hline 006 & $\begin{array}{l}\text { Kata simbok saat aku bayi aku } \\
\text { selalu mencari-cari dadanya yang } \\
\text { kewer-kewer. }\end{array}$ & 16 & $\begin{array}{l}\text { She said I was always looking } \\
\text { for her hanging breast when I } \\
\text { was a baby. }\end{array}$ & 14 \\
\hline 007 & $\begin{array}{l}\text { Gembolan itu membuat tubuhku } \\
\text { bertambah berat, dan selalu } \\
\text { nglawer nglawer. }\end{array}$ & 16 & $\begin{array}{l}\text { It was as though I was carrying } \\
\text { a pair of balls on my chest that } \\
\text { kept my body heavy and forever } \\
\text { bouncing. }\end{array}$ & 14 \\
\hline 008 & $\begin{array}{l}\text { "Ini entrok }{ }^{3} \text {," Kata Tinah } \\
{ }^{3} \text { bra atau BH }\end{array}$ & 17 & "This is a bra", Tinah said & 15 \\
\hline 009 & $\begin{array}{l}\text { "Itu lho, mbok, kain buat nutup } \\
\text { susuku biar kenceng. Seperti punya } \\
\text { Tinah" }\end{array}$ & 17 & $\begin{array}{l}\text { "it's something to cover up my } \\
\text { breast, to keep them firm. Lika } \\
\text { Tinah's." }\end{array}$ & 15 \\
\hline 010 & $\begin{array}{l}\text { "Oalah, Nduk, seumur-umur tidak } \\
\text { pernah aku punya entrok. }\end{array}$ & 17 & $\begin{array}{l}\text { "Oh, Nduk. I've never had a bra } \\
\text { in my a whole life. }\end{array}$ & 15 \\
\hline 011 & p bisa diperas to. & 17 & $\begin{array}{l}\text { Look, my breasts are still } \\
\text { squeezable, right? }\end{array}$ & 15 \\
\hline 012 & $\begin{array}{l}\text { "Aku setiap hari di sini, Ni. Malam } \\
\text { tidur di sini. Pagi sampai siang } \\
\text { nguli di sini. Nunut di sini." }\end{array}$ & 21 & $\begin{array}{l}\text { "I'am here every day, Ni. I sleep } \\
\text { here at night. From morning 'till } \\
\text { afternoon I work as a porter } \\
\text { here. I live here. }\end{array}$ & 18 \\
\hline 013 & Los-los begitu sepi. & 21 & The stalls were empty. & 19 \\
\hline 014 & ang yang berbelanja atau & 21 & $\begin{array}{l}\text { No one was shopping or } \\
\text { browsing around. }\end{array}$ & 19 \\
\hline 015 & $\begin{array}{l}\text { Di depan kami, di belakang, juga di } \\
\text { samping, perempuan-perempuan } \\
\text { menggendong tenggok. } \\
{ }^{5} \text { wadah barang untuk dijajakan }\end{array}$ & 21 & $\begin{array}{l}\text { Ahead of us, behind us, and all } \\
\text { around us, woman were } \\
\text { carrying their baskets of goods } \\
\text { to Ngrangat }\end{array}$ & $\begin{array}{l}19- \\
20\end{array}$ \\
\hline 016 & $\begin{array}{l}\text { "Oalah, Nduk, seumur-umur tidak } \\
\text { pernah aku punya entrok. }\end{array}$ & 17 & $\begin{array}{l}\text { "Oh, Nduk. I've never had a bra } \\
\text { in my a whole life. }\end{array}$ & 15 \\
\hline 017 & $\begin{array}{l}\text { "sst!Yuk, aku mau } \\
\text { cerita...Dengarkan, Yuk! }\end{array}$ & 14 & $\begin{array}{l}\text { "Shhh!Yuk, I want to tell you } \\
\text { something...Listen, Yuk! }\end{array}$ & 12 \\
\hline 018 & $\begin{array}{l}\text { Kabar Yu yem telah menjadi } \\
\text { gendakan }\end{array}$ & 29 & $\begin{array}{l}\text { The gossip that Yu Yem was } M r . \\
\text { Suyat's mistress spread like } \\
\text { wildfire. }\end{array}$ & 26 \\
\hline
\end{tabular}




\begin{tabular}{|c|c|c|c|c|}
\hline & ${ }^{7}$ Selingkuhan atau simpanan & & & \\
\hline 019 & $\begin{array}{l}\text { Di dekatnya ada jumbleng. }{ }^{30} \\
{ }^{30} \text { toilet yang dibangun di tempat } \\
\text { terbuka, kotoran langsung masuk } \\
\text { ke tanah tanpa disiram air. }\end{array}$ & 30 & $\begin{array}{l}\text { I thought the pain might have } \\
\text { come from my needing to go to } \\
\text { the toilet. }\end{array}$ & 27 \\
\hline 020 & $\begin{array}{l}\text { Orang kayak kita bagiannya } \\
\text { ngoncek telo. } \\
{ }^{9} \text { mengupas singkong }\end{array}$ & 34 & $\begin{array}{l}\text { People like us are meant to peel } \\
\text { cassavas. }\end{array}$ & 31 \\
\hline 021 & $\begin{array}{l}\text { Lalu mbah Noto mengalami saat } \\
\text { goro-goro terjadi di wetan kali. }{ }^{10} \\
10 \text { seberang timur kali }\end{array}$ & 36 & $\begin{array}{l}\text { Old man Noto also lived } \\
\text { through the unreast that } \\
\text { happened across the river. }\end{array}$ & 33 \\
\hline 022 & $\begin{array}{l}\text { Anak laki-lakinya, Teja, kini } \\
\text { meneruskan garis nasib keluarga itu } \\
\text { untuk menjual okol }{ }^{11} \text { yang } \\
\text { dimiliki. } \\
{ }^{11} \text { fisik, otot }\end{array}$ & 37 & $\begin{array}{l}\text { His son, Teja, inherited the same } \\
\text { fate of having to make la living } \\
\text { from his brute strength. }\end{array}$ & 33 \\
\hline 023 & $\begin{array}{l}\text { Lalu mbah Noto mengalami saat } \\
\text { goro-goro terjadi di wetan kali. }{ }^{10} \\
{ }^{10} \text { seberang timur kali }\end{array}$ & 36 & $\begin{array}{l}\text { Old man Noto also lived through } \\
\text { the unreast that happened } \\
\text { across the river. }\end{array}$ & 33 \\
\hline 024 & Sudah, ga usah neko-neko. & 17 & You don't need it. & 15 \\
\hline 025 & $\begin{array}{l}\text { Samar-samar, aku hanya ingat } \\
\text { Bapak meninggalkan kami waktu } \\
\text { aku pertama kali bisa mengangkat } \\
\text { panic yang airnya mendidih dari } \\
\text { pawon. } \\
{ }^{4} \text { tungku tradisional yang terbuat } \\
\text { dari batu bata dengan bahan bakar } \\
\text { kayu }\end{array}$ & 18 & $\begin{array}{l}\text { All I can remember, vaquely, is } \\
\text { that it was around the time when } \\
\text { I could carry a pot of boiling } \\
\text { water from the stove. }\end{array}$ & 15 \\
\hline
\end{tabular}

\section{Data 001}

\begin{tabular}{|l|c|l|c|}
\hline \multicolumn{1}{|c|}{ TSu } & Hal & TSa & Hal \\
&. & & "The times have changed, mom. \\
\hline $\begin{array}{l}\text { Zaman sudah berubah, bu. Semuanya sudah } \\
\text { berbeda." }\end{array}$ & 13 & $\begin{array}{l}\text { (11 } \\
\text { Everything is different." }\end{array}$ \\
\hline
\end{tabular}


Pada data 001 dalam terjemahan di atas, dapat dilihat bahwa terdapat ideologi pelokalan dalam proses penerjemahan dari TSu ke dalam TSa pada kata 'bu' dalam teks sumber. Pada penerjemahan 'bu' ke dalam bahasa Inggris menjadi 'mom', penerjemah menggunakan ideologi pelokalan dalam transfer budaya tersebut. Kata tersebut termasuk ke dalam istilah budaya Indonesia karena panggilan untuk orang tua perempuan adalah 'bu'. Penerjemah menggunakan transfer lokal dengan menggunakan kata ' mom' karena pesan yang ingin disampaikan dalam teks sumber ke dalam teks sasaran dapat dipahami dengan baik oleh pembaca novel.

\section{Data 002}

\begin{tabular}{|l|l|l|l|}
\hline \multicolumn{1}{|c|}{ TSu } & Hal. & TSa & Hal. \\
\hline $\begin{array}{l}\text { "Takgendong...cucuku...takgendong...cucu } \\
\text { ku" }\end{array}$ & 14 & $\begin{array}{l}\text { "I'll carry you....my } \\
\text { grandchildren" }\end{array}$ & 12 \\
\hline
\end{tabular}

Pada data 002 dalam terjemahan di atas, dapat dilihat bahwa terdapat ideologi pelokalan dalam proses penerjemahan dari TSu ke dalam TSa pada kata 'takgendong' dalam bahasa Indonesia. Pada penerjemahan 'takgendong' ke dalam bahasa Inggris menjadi ' $I$ 'll carry' penerjemah menggunakan ideologi pelokalan dalam transfer budaya tersebut. Kata tersebut termasuk ke dalam istilah budaya Indonesia karena penggunaan kata 'takgendong' yang berarti bahwa seseorang melakukan pekerjaan menggondong terhadap orang lain. Pada data 002 , terlihat bahwa penerjemah menggunakan transfer lokal dengan menerjemahkannya menjadi klausa 'I'll carry' yang berarti bahwa 'saya mengangkat'. Penggunaan I'll carry dalam terjemahan tersebut disesuaikan dengan budaya bahasa sasaran karena pesan yang ingin disampaikan dalam teks sumber ke dalam teks sasaran dapat dipahami dengan baik oleh pembaca novel dan juga dalam bahasa sasaran.

\section{Data 003}

\begin{tabular}{|l|l|l|l|}
\hline \multicolumn{1}{|c|}{ TSu } & Hal. & \multicolumn{1}{|c|}{ TSa } & Hal. \\
\hline $\begin{array}{l}\text { "Takgendong...cucuku...takgendong...ke } \\
\text { mana-mana!"” }\end{array}$ & 14 & $\begin{array}{l}\text { "I'll carry you ....my } \\
\text { grandchildren ...I'll carry you } \\
\text {...everywhere" }\end{array}$ & 13 \\
\hline
\end{tabular}

Pada data 003 dalam terjemahan di atas, dapat dilihat bahwa terdapat ideologi pelokalan dalam proses penerjemahan dari TSu ke dalam TSa pada kata 'cucuku' dalam bahasa Indonesia. Pada penerjemahan 'cucuku' ke dalam bahasa Inggris menjadi 'my 
grandchildren', penerjemah menggunakan ideologi pelokalan dalam transfer budaya tersebut. Pada data 003, terlihat bahwa penerjemah menggunakan transfer lokal dengan menerjemahkannya menjadi 'my grandchildren'. Penggunaan my grandchildren dalam terjemahan tersebut disesuaikan dengan budaya bahasa sasaran karena pesan yang ingin disampaikan dalam teks sumber ke dalam teks sasaran dapat dipahami dengan baik oleh pembaca novel dan juga dalam bahasa sasaran.

\section{Data 004}

\begin{tabular}{|c|c|l|c|}
\hline TSu & Hal. & \multicolumn{1}{|c|}{ TSa } & Hal. \\
\hline "Oh...Ibu" & 14 & "Oh...Mother" & 13 \\
\hline
\end{tabular}

Pada data 001 dalam terjemahan di atas, dapat dilihat bahwa terdapat ideologi pelokalan dalam proses penerjemahan dari TSu ke dalam TSa pada kata 'ibu' dalam bahasa Indonesia. Pada penerjemahan 'ibu' ke dalam bahasa Inggris menjadi 'mother', penerjemah menggunakan ideologi pelokalan dalam transfer budaya tersebut. Kata tersebut termasuk ke dalam istilah budaya Indonesia karena panggilan untuk orang tua perempuan adalah 'ibu'. Penerjemah menggunakan transfer lokal dengan menggunakan kata 'mother' karena pesan yang ingin disampaikan dalam teks sumber ke dalam teks sasaran dapat dipahami dengan baik oleh pembaca novel.

\section{Data 005}

\begin{tabular}{|l|l|l|l|}
\hline \multicolumn{1}{|c|}{ TSu } & Hal. & \multicolumn{1}{|c|}{ TSa } & Hal. \\
\hline $\begin{array}{l}\text { Simbok bilang aku sudah mringkili. } \\
{ }^{1} \text { Payudara yang mulai tumbuh }\end{array}$ & 16 & $\begin{array}{l}\text { "Simbok told me that I was } \\
\text { growing } \text { up }\end{array}$ & 13 \\
\hline
\end{tabular}

Pada data 005 dalam terjemahan di atas, dapat dilihat bahwa terdapat ideologi pelokalan dalam proses penerjemahan dari TSu ke dalam TSa pada kata 'mringkili' yang merupakan istilah Jawa yang berarti payudaya yang mulai tumbuh dalam bahasa Indonesia. Pada penerjemahan 'mringkili' ke dalam bahasa Inggris menjadi 'growing up', penerjemah menggunakan ideologi pelokalan dalam transfer budaya tersebut. Pada data 005, terlihat bahwa penerjemah menggunakan transfer lokal dengan menerjemahkannya menjadi ' growing up' yang berarti tumbuh. Penggunaan 'growing up' dalam terjemahan tersebut disesuaikan dengan budaya bahasa sasaran karena pesan yang ingin disampaikan dalam teks sumber ke 
dalam teks sasaran dapat dipahami dengan baik oleh pembaca novel dan juga dalam bahasa sasaran.

\section{Pemancanegaraan dalam Terjemahan Novel Entrok Karya Okky Madasari}

Dalam menerjemahkan istilah budaya, tidak dapat dipungkiri bahwa penerjemah sering menggunakan ideologi foreignisasi (pemancanegaraan) yaitu ideologi yang berorientasi pada bahasa sumber, yakni bahwa yang betul, berterima, dan baik adalah yang sesuai dengan selera dan harapan pembaca, serta penerbit yang menginginkan kehadiran kebudayaan bahasa sumber atau yang menganggap kehadiran kebudayaan asing bermanfaat bagi masyarakat.

Tabel 4.2

Pemancanegaraan dalam Terjemahan Novel Entrok

\begin{tabular}{|c|c|c|c|c|}
\hline $\begin{array}{l}\text { No } \\
\text { Urut } \\
\text { Data }\end{array}$ & TSu & Hal. & TSa & Hal. \\
\hline 026 & Ibu, lihat ini Bu. KTP-ku baru. & 13 & $\begin{array}{l}\text { Mother, look at this, mother. My } \\
\text { new KTP. } \\
{ }^{3} \text { ID Card }\end{array}$ & 11 \\
\hline 027 & Ka Te Pe, Bu! & 13 & "Ka-Tay-Pay, mother!" & 11 \\
\hline 028 & "Tape? Aku mau buat tape." & 13 & $\begin{array}{l}\text { "Tape } ?^{4} \text { I want to make some } \\
\text { tape? } \\
4\end{array}$ & 11 \\
\hline 029 & $\begin{array}{l}\text { "Bukan tape, bu," kataku sambil } \\
\text { mengusap usap rambut. }\end{array}$ & 13 & $\begin{array}{l}\text { Not tape, mother, "I say as I } \\
\text { stroke the white hair of the } \\
\text { woman. }\end{array}$ & 11 \\
\hline 030 & "Kamu pulang sendiri, Nduk? & 14 & $\begin{array}{l}\text { "you'are back on your own, } \\
\text { Nduk? } \\
{ }^{6} \text { child }\end{array}$ & 12 \\
\hline 031 & $\begin{array}{l}\text { "sst!Yuk, aku mau } \\
\text { cerita...Dengarkan, Yuk! }\end{array}$ & 14 & $\begin{array}{l}\text { "Shhh!Yuk, I want to tell you } \\
\text { something...Listen, Yuk! }\end{array}$ & 12 \\
\hline 032 & "Kamu pulang Rahayu?" & 14 & "You are back, Rahayu?" & 12 \\
\hline 033 & $\begin{array}{l}\text { Yang kutahu saat itu hanya bau } \\
\text { badan Simbok dan dadanya yang } \\
\text { kenyal dan mengeluarkan susu } \\
\text { putih. }\end{array}$ & 15 & $\begin{array}{l}\text { All I knew then was the scent of } \\
\text { Simbok's body and the spongy } \\
\text { feel of her breast that dripped } \\
\text { milk. }\end{array}$ & 13 \\
\hline 034 & $\begin{array}{l}\text { Aku heran bagaimana Tinah, } \\
\text { anak Paklik, bisa begitubebas. }\end{array}$ & $\begin{array}{l}16- \\
17\end{array}$ & $\begin{array}{l}\text { I wondered how Tinah, Paklik's } \\
{ }^{7} \text { daughter. } \\
{ }^{7} \text { uncle }\end{array}$ & 14 \\
\hline 035 & Aku tidak punya Bapak, Bulik. & 19 & "I don't have a father, Bulik. ${ }^{8}$ I & 17 \\
\hline
\end{tabular}




\begin{tabular}{|l|l|l|l|l|}
\hline & Aku tifak tahu di mana dia. & & don't know where he is. & \\
\hline 036 & $\begin{array}{l}\text { "Nggak nunggu siapa-siapa, } \\
\text { Kang. Cuma duduk-duduk." }\end{array}$ & 21 & $\begin{array}{l}\text { "I aunt not waiting for anyone, } \\
\text { Kang. }\end{array}$ & 18 \\
9honorific for a young man & \\
\hline
\end{tabular}

Berikut ini analisis data pemancanegaraan dalam terjemahan novel Entrok:

\section{Data 026}

\begin{tabular}{|l|l|l|l|}
\hline TSu & Hal. & TSa & Hal. \\
\hline Ibu, lihat ini Bu. KTP-ku baru. & 13 & $\begin{array}{l}\text { Mother, look at this, mother. } \\
\text { My new KTP. }{ }^{3} \\
\text { IID Card }\end{array}$ & 11 \\
\hline
\end{tabular}

Pada data 026, pemancanegaraan sebagai upaya untuk memperkenalkan budaya Indonesia ke kancah internasional disuguhkan melalui penggunaan prosedur catatan kaki pada penerjemahan 'KTP'. Ideologi yang digunakan oleh penerjemah sebagai upaya untuk memperkenalkan istilah terkait dengan kartu identitas penduduk. Pada penerjemahannya, terdapat catatan kaki dengan penjelasan 'ID Card' yang bermakna bahwa KTP adalah 'ID card yang digunakan sebagai tanda pengenal penduduk'.

\section{Data 027}

\begin{tabular}{|l|l|l|l|}
\hline TSu & Hal. & TSa & Hal. \\
\hline Ka Te Pe, Bu! & 13 & "Ka-Tay-Pay, mother!" & 11 \\
\hline
\end{tabular}

Pada data 027, pemancanegaraan sebagai upaya untuk memperkenalkan budaya Indonesia ke kancah internasional disuguhkan melalui penerjemahan dari ejaan $\mathrm{Ka} \mathrm{Te} \mathrm{Pe}$ yang merujuk pada istilah 'KTP'. Ideologi yang digunakan oleh penerjemah sebagai upaya untuk memperkenalkan istilah terkait dengan kartu identitas penduduk. Pada penerjemahannya, terdapat penyesuaian bunyi 'Ka-Tay-Pay' yang bermakna bahwa KTP adalah 'ID card yang digunakan sebagai tanda pengenal penduduk'.

\section{Data 028}




\begin{tabular}{|l|l|l|l|}
\hline TSu & Hal. & TSa & Hal. \\
\hline $\begin{array}{l}\text { "Tape? Aku mau } \\
\text { buat tape." }\end{array}$ & 13 & $\begin{array}{l}\text { "Tape? }{ }^{4} \text { I want to make some } \\
\text { tape? } \\
4\end{array}$ & 11 \\
& & $\begin{array}{l}\text { Snack made of fermented } \\
\text { cassava or rice }\end{array}$ & \\
\hline
\end{tabular}

Pada data 028, pemancanegaraan sebagai upaya untuk memperkenalkan budaya Indonesia ke kancah internasional disuguhkan melalui penggunaan prosedur catatan kaki pada penerjemahan 'tape'. Ideologi yang digunakan oleh penerjemah sebagai upaya untuk memperkenalkan istilah makanan yang terbuat dari singkong yaitu 'tape'. Pada penerjemahannya, terdapat catatan kaki dengan penjelasan 'Snack made offermented cassava or rice' yang berarti bahwa makanan yang terbuat dari singkong yang dikasih ragi.

\section{Data 029}

\begin{tabular}{|l|l|l|l|}
\hline TSu & Hal. & TSa & Hal. \\
\hline $\begin{array}{l}\text { "Bukan tape, bu," kataku } \\
\text { sambil mengusap usap rambut. }\end{array}$ & 13 & $\begin{array}{l}\text { Not tape, mother, " I say as I stroke the } \\
\text { white hair of the woman. }\end{array}$ & 11 \\
\hline
\end{tabular}

Pada data 029, pemancanegaraan sebagai upaya untuk memperkenalkan budaya Indonesia ke kancah internasional disuguhkan melalui penggunaan prosedur catatan kaki pada penerjemahan 'tape'. Ideologi yang digunakan oleh penerjemah sebagai upaya untuk memperkenalkan istilah makanan yang terbuat dari singkong yaitu 'tape'. Pada penerjemahannya, terdapat catatan kaki dengan penjelasan 'Snack made offermented cassava or rice' yang berarti bahwa makanan yang terbuat dari singkong yang dikasih ragi.

\section{Data 030}

\begin{tabular}{|l|l|l|l|}
\hline TSu & Hal. & TSa & Hal. \\
\hline "Kamu pulang sendiri, Nduk? & 14 & $\begin{array}{l}\text { "you'are back on your own, Nduk? } \\
{ }^{6} \text { child }\end{array}$ & 12 \\
& & \\
\hline
\end{tabular}

Pada data 030, pemancanegaraan sebagai upaya untuk memperkenalkan budaya Indonesia ke kancah internasional disuguhkan melalui penggunaan prosedur catatan kaki pada penerjemahan 'nduk'. Ideologi yang digunakan oleh penerjemah sebagai upaya untuk memperkenalkan panggilan untuk anak kecil perempuan yaitu 'Nduk'. Pada 
penerjemahannya, terdapat catatan kaki dengan penjelasan 'child' yang berarti bahwa Nduk adalah panggilan yang diperuntukkan untuk anak perempuan yang masih kecil.

\section{Prosedur Penerjemahan Pelokalan dalam Terjemahan Novel Entrok Karya Okky Madasari}

Pada sub bagian ini akan dibahas tentang prosedur penerjemahan dengan menggunakan acuan teori dari Newmark. Berdasarkan temuan penelitian, terdapat beberapa prosedur yang digunakan yang dappat dilihat pada data berikut:

\begin{tabular}{|l|c|c|}
\hline \multicolumn{1}{|c|}{ Prosedur Penelitian } & Jumlah Data & Persentase \\
\hline Penerjemahan harfiah & 15 & $60 \%$ \\
\hline Pergeseran & 7 & $28 \%$ \\
\hline Komponen Budaya & 2 & $8 \%$ \\
\hline Catatan Kaki & 1 & $4 \%$ \\
\hline & 25 & $100 \%$ \\
\hline
\end{tabular}

\section{Data 001}

\begin{tabular}{|l|l|l|l|}
\hline \multicolumn{1}{|c|}{ TSu } & Hal. & \multicolumn{1}{c|}{ TSa } & Hal. \\
\hline $\begin{array}{l}\text { Zaman sudah berubah, bu. } \\
\text { Semuanya sudah berbeda." }\end{array}$ & 13 & $\begin{array}{l}\text { "The times have changed, mom. } \\
\text { Everything is different." }\end{array}$ & 11 \\
\hline
\end{tabular}

Pada data 001, pada penerjemahan 'bu', penerjemah menggunakan prosedur penerjemahan harfiah dengan menggunakan terjemahan 'mom' dalam teks sasaran. Hal ini sudah tepat karena 'mom' dalam bahasa Inggris merupakan padanan dari kata ibu dalam bahasa Indonesia.

\section{Data 002}

\begin{tabular}{|l|l|l|l|}
\hline \multicolumn{1}{|c|}{ TSu } & Hal. & \multicolumn{1}{|c|}{ TSa } & Hal. \\
\hline $\begin{array}{l}\text { "Takgendong...cucuku...takgendong...cuc } \\
\text { uku" }\end{array}$ & 14 & $\begin{array}{l}\text { "I'll carry you ....my } \\
\text { grandchildren }\end{array}$ & 12 \\
\hline
\end{tabular}

Pada data 002 dalam terjemahan di atas, penerjemah menggunakan prosedur penerjemahan pergeseran. Pada penerjemahan 'takgendong' diterjemahkan ke dalam bahasa Inggris menjadi 'I'll carry'. Penerjemah mengubah verba dalam bahasa Indonesia menjadi 
klausa. Pergeseran ini memang perlu dilakukan mengingat bahwa struktur dalam bahasa Indonesia berbeda dengan bahasa Inggris.

Data 003

\begin{tabular}{|l|l|l|l|}
\hline \multicolumn{1}{|c|}{ TSu } & Hal. & \multicolumn{1}{c|}{ TSa } & Hal. \\
\hline $\begin{array}{l}\text { "Takgendong...cucuku...takgendong...ke } \\
\text { mana-mana!"” }\end{array}$ & 14 & $\begin{array}{l}\text { "I'll carry you....my } \\
\text { grandchildren...I'll carry you } \\
\text {..everywhere" }\end{array}$ & 13 \\
\hline
\end{tabular}

Pada data 003, pada penerjemahan 'cucuku', penerjemah menggunakan prosedur penerjemahan pergeseran dengan menggunakan terjemahan 'my grandchildren' dalam teks sasaran. Pada tek sumber terdiri dari satu kata sedangkan pada teks sasaran terdiri dari dua kata. Penggunaan 'ku' dalam bahasa Indonesia berada di akhir kata sedangkan dalam bahasaa Inggris berada di awal kata. Penerjemahan ini sudah tepat karena 'my granchildren' dalam bahasa Inggris merupakan padanan dari kata cucuku dalam bahasa Indonesia.

\section{Kesepadanan Penerjemahan Pemancanegaraan dalam Terjemahan Novel Entrok Karya Okky Madasari}

Konsep kesepadanan yang digunakan dalam analisis ini adalah kesepadanan yang diungkapkan oleh Eugene A. Nida (1964: 165) yang membagi kesepadanan menjadi dua, yakni kesepadanan formal dan kesepadanan dinamis. Kesepadanan formal berorientasi pada teks sumber sedangkan kesepadanan dinamis fokus langsung kepada pesan dalam bahasa sumber untuk disampaikan kapada pembaca. Pada pemancanegaraan, kesepadanan yang paling dominan digunakan dalam terjemahan adalah kesepadanan formal yang berorientasi pada teks sumber.

Berikut ini analisis data kesepadanan pada pemancanegaraan dalam terjemahan novel Entrok:

\section{Data 026}

\begin{tabular}{|l|l|l|l|}
\hline TSu & Hal. & TSa & Hal. \\
\hline Ibu, lihat ini Bu. KTP-ku baru. & 13 & $\begin{array}{l}\text { Mother, look at this, mother. My } \\
\text { new KTP. }\end{array}$ & 11 \\
& & \\
&
\end{tabular}

Pada data 026, pada penerjemahan 'KTP', penerjemah menggunakan kesepadanan formal dengan tetap menggunakan terjemahan KTP dalam teks sasaran. Hal ini sudah tepat karena penerjemah memberikan catatan kaki yang disesuaikan dengan makna yang 
terkandung di dalam teks sasaran dan bisa berterima dalam teks sasaran dan bisa menyampaikan maksud dari teks sumber.

\section{Data 027}

\begin{tabular}{|l|l|l|l|}
\hline TSu & Hal. & TSa & Hal. \\
\hline Ka Te Pe, Bu! & 13 & "Ka-Tay-Pay, mother!” & 11 \\
\hline
\end{tabular}

Pada data 026, pada penerjemahan 'Ka Te Pe', penerjemah menggunakan kesepadanan formal dengan dengan tetap menggunakan Ka Tay Pay dalam teks sasaran. Penggunaan kesepadanan formal ini sudah tepat dan bisa dipahami dalam teks sasaran serta sudah dapat menyampaikan pesan yang terdapat dalam teks sumber.

\section{Data 028}

\begin{tabular}{|l|l|l|l|}
\hline TSu & Hal. & TSa & Hal. \\
\hline "Tape? Aku mau buat tape." & 13 & "Tape? ${ }^{4}$ I want to make some tape? & 11 \\
& & & \\
\hline
\end{tabular}

Pada data 028, pada penerjemahan 'tape', penerjemah menggunakan kesepadanan formal dengan tetap menggunakan terjemahan 'tape' dalam teks sasaran. Hal ini sudah tepat karena penerjemah memberikan catatan kaki yang disesuaikan dengan makna yang terkandung di dalam teks sasaran dan bisa berterima dalam teks sasaran dan bisa menyampaikan maksud dari teks sumber.

\section{Data 029}

\begin{tabular}{|l|l|l|l|}
\hline TSu & Hal. & TSa & Hal. \\
\hline $\begin{array}{l}\text { "Bukan tape, bu," } \\
\text { kataku sambil } \\
\text { mengusap usap } \\
\text { rambut. }\end{array}$ & 13 & $\begin{array}{l}\text { Not tape, mother, "I say as } \\
\text { I stroke the white hair of the } \\
\text { woman. }\end{array}$ & 11 \\
\hline
\end{tabular}

Pada data 029, pada penerjemahan 'tape', penerjemah menggunakan kesepadanan formal dengan tetap menggunakan terjemahan 'tape' dalam teks sasaran. Hal ini sudah tepat karena penerjemah memberikan catatan kaki pada teks sebelumnya yang disesuaikan dengan makna yang terkandung di dalam teks sasaran dan bisa berterima dalam teks sasaran dan bisa menyampaikan maksud dari teks sumber.

\section{Data 030}




\begin{tabular}{|l|l|l|l|}
\hline TSu & Hal. & TSa & Hal. \\
\hline “Kamu pulang sendiri, Nduk? & 14 & $\begin{array}{l}\text { "you'are back on your own, } \\
\text { Nduk? }\end{array}$ & 12 \\
${ }^{6}$ child & \\
\hline
\end{tabular}

Pada data 030, pada penerjemahan 'Nduk', penerjemah menggunakan kesepadanan formal dengan tetap menggunakan terjemahan 'Nduk' dalam teks sasaran. Hal ini sudah tepat karena penerjemah memberikan catatan kaki yang disesuaikan dengan makna yang terkandung di dalam teks sasaran dan bisa berterima dalam teks sasaran dan bisa menyampaikan maksud dari teks sumber.

\section{Data 031}

\begin{tabular}{|l|l|l|l|}
\hline TSu & Hal. & TSa & Hal. \\
\hline $\begin{array}{l}\text { "sst!Yuk, aku mau cerita...Dengarkan, } \\
\text { Yuk! }\end{array}$ & 14 & $\begin{array}{l}\text { "Shhh!Yuk, I want to tell you } \\
\text { something...Listen, Yuk! }\end{array}$ & 12 \\
\hline
\end{tabular}

Pada data 028, pada penerjemahan 'yuk', penerjemah menggunakan kesepadanan formal dengan tetap menggunakan terjemahan 'yuk' dalam teks sasaran. Hal ini sudah tepat karena penerjemah menggunakan bahasa yang bisa dipahami oleh pengguna bahasa sumber dan bahasa sasaran dan bisa berterima dalam teks sasaran dan bisa menyampaikan maksud dari teks sumber.

\section{Data 032}

\begin{tabular}{|l|l|l|l|}
\hline TSu & Hal. & TSa & Hal. \\
\hline "Kamu pulang Rahayu?" & 14 & "You are back, Rahayu? " & 12 \\
\hline
\end{tabular}

Pada data 032, pada penerjemahan 'Rahayu', penerjemah menggunakan kesepadanan formal dengan tetap menggunakan terjemahan 'Rahayu' dalam teks sasaran. Hal ini sudah tepat karena penerjemahan nama orang yang tetap dipertahankan oleh penerjemah.

\section{Data 033}

\begin{tabular}{|l|l|l|l|}
\hline TSu & Hal. & TSa & Hal. \\
\hline $\begin{array}{l}\text { Yang kutahu saat itu hanya bau badan } \\
\text { Simbok dan dadanya yang kenyal dan } \\
\text { mengeluarkan susu putih. }\end{array}$ & 15 & $\begin{array}{l}\text { All I knew then was the scent of } \\
\text { Simbok's body and the spongy } \\
\text { feel of her breast that dripped } \\
\text { milk. }\end{array}$ & 13 \\
\hline
\end{tabular}


Pada data 033, pada penerjemahan 'simbok', penerjemah menggunakan kesepadanan formal dengan tetap menggunakan terjemahan 'simbok' dalam teks sasaran. Pada teks sebelumnya sudah dijelaskan dengan menggunakan catatan kaki tentang makna simbok sehingga sudah jelas dalam bahasa sasaran. Pada terjemahan ini sudah tepat karena penerjemah menggunakan bahasa yang bisa dipahami oleh pengguna bahasa sumber dan bahasa sasaran dan bisa berterima dalam teks sasaran.

\section{Data 034}

\begin{tabular}{|l|l|l|l|}
\hline TSu & Hal. & TSa & Hal. \\
\hline $\begin{array}{l}\text { Aku heran bagaimana Tinah, } \\
\text { anak Paklik, bisa begitubebas. }\end{array}$ & $16-17$ & $\begin{array}{l}\text { I wondered how Tinah, } \\
\text { Paklik's 7 daughter. } \\
7 \text { uncle }\end{array}$ & 14 \\
\hline
\end{tabular}

Pada data 034, pada penerjemahan 'Paklik', penerjemah menggunakan kesepadanan formal dengan tetap menggunakan terjemahan 'Paklik' dalam teks sasaran. Hal ini sudah tepat karena penerjemah memberikan catatan kaki yang disesuaikan dengan makna yang terkandung di dalam teks sasaran dan bisa berterima dalam teks sasaran dan bisa menyampaikan maksud dari teks sumber.

\section{Data 035}

\begin{tabular}{|l|l|l|l|}
\hline TSu & Hal. & TSa & Hal. \\
\hline $\begin{array}{l}\text { Aku tidak punya Bapak, Bulik. Aku tifak } \\
\text { tahu di mana dia. }\end{array}$ & 19 & $\begin{array}{l}\text { "I don't have a father, Bulik. }{ }^{8} \text { I } \\
\text { don't know where he is. }\end{array}$ & 17 \\
& & \begin{tabular}{l}
${ }^{8}$ aunt \\
\hline
\end{tabular}
\end{tabular}

Pada data 035, pada penerjemahan 'Bulik', penerjemah menggunakan kesepadanan formal dengan tetap menggunakan terjemahan 'Bulik' dalam teks sasaran. Hal ini sudah tepat karena penerjemah memberikan catatan kaki yang disesuaikan dengan makna yang terkandung di dalam teks sasaran dan bisa berterima dalam teks sasaran dan bisa menyampaikan maksud dari teks sumber.

\section{Data 036}




\begin{tabular}{|c|c|c|c|}
\hline $\begin{array}{l}\text { "Nggak nunggu siapa-siapa, Kang. } \\
\text { Cuma duduk-duduk." }\end{array}$ & 21 & $\begin{array}{l}\text { "I am not waiting for anyone, } \\
\text { Kang. } \\
{ }^{9} \text { honorific for a young man }\end{array}$ & 18 \\
\hline
\end{tabular}

Pada data 034, pada penerjemahan 'Kang', penerjemah menggunakan kesepadanan formal dengan tetap menggunakan terjemahan 'Kang' dalam teks sasaran. Hal ini sudah tepat karena penerjemah memberikan catatan kaki yang disesuaikan dengan makna yang terkandung di dalam teks sasaran dan bisa berterima dalam teks sasaran dan bisa menyampaikan maksud dari teks sumber.

\section{Simpulan}

Pertama, terdapat pelokalan sebanyak 25 data dan pemancanegaraan sebanyak 11 data dalam terjemahan novel Entrok. Pelokalan terjadi karena penerjemah ingin mempertahankan terjemahan dalam teks sasaran sehingga menyesuaikan dengan teks sumber. Adapun pemancanegaraan terjadi karena penerjemah ingin mempertahankan budaya sumber pada saat menerjemahkan ke dalam teks sasaran.

Kedua, prosedur penerjemahan yang ditemukan pada pelokalan adalah harfiah $60 \%$, pergeseran 28\%, kesepadanan budaya $8 \%$, dan catatan kaki $4 \%$ sedangkan pada pemancanegaraan adalah catatan kaki sebesar 54,5\%, transferensi 27,2\%, dan harfiah 18,2\%.

Ketiga, pada hasil terjemahan, terlihat bahwa terdapat dua kesepadanan yang digunakan dalam terjemahan, yaitu kesepadanan dinamis dan kesepadanan formal. Kesepadanan dinamis fokus pada pembaca sedangkan kesepadanan formal fokus pada bentuk

\section{Daftar Pustaka}

Albakry, M. 2004. "Linguistics and Cultural Issues in Literary Translation". Translation Journal Volume 8. No. 3 July 2014.

Ayoub, Shaifta. 2014. Cases of "Domestication" and "Foreignization" in the Translation of Urdu Short Story into English: A Preliminary Inquiry. EUROPEAN ACADEMIC RESEARCH Vol. II, Issue 4/ July 2014 Impact Factor: 3.1 (UIF) DRJI Value: 5.9 (B+). 
Baawaidhan, Awadh. 2016. Applying Foreignization and Domestication in Translating Arabic Dialectical Expressions into English. International Journal of Linguistics ISSN 1948-5425 2016, Vol. 8, No. 4.

Haque, Ziaul Md. 2012. International Journal of English Linguistics, Vol.2, $\quad$ No. 6.2012. Published by Canadian Center of Science and Education.

Hartono, Rudi. 2011. "Penerjemahan Idiom dan Gaya Baasa (Metafora, Kiasan,

Personifikasi, dan Aliterasi) dalam Novel To Kill A Mockingbird dari Bahasa Inggris ke Bahasa Indonesia (Pendekatan Kritik Holistik)”. Penelitian. Surakarta: Program Pascasarjana UNS.

Hoed, Benny Hoedoro. 2006. Penerjemahan dan Kebudayaan. Jakarta: PT Dunia Pustaka Jaya. 2003. Penelitian di Bidang Penerjemahan. Makalah untuk Lokakarya Penelitian STBA LIA, Wisma Karya Sartika, Cipanas.

Newmark, Peter. 1988. A Textbook of Translation. London: Prentice Hall International.

Shahabi, Hassan \& Raheleh Rezaei Shams Abad. 2016. A Study of Domestication and Foreignization of Culture-Specific Items in Two Persian Translations of the Old Man and the Sea. Journal of Language Sciences \& Linguistics. Vol., 4 (3), 191-198, 2016. Available online at http://www.jlsljournal.com. ISSN 21480672 @2016.

Siregar, T, Roswani dkk. 2015. Domestication and Foreignization In The Process Of Translation of the 8th Habit by Stephen R. Covey into Bahasa Indonesia. IOSR Journal Of Humanities And Social Science (IOSR-JHSS) Volume 20, Issue 4, Ver. II (Apr. 2015), PP 53-63 e-ISSN: 2279-0837, p-ISSN: 2279-0845. www.iosrjournals.org.

Sudana, M. D, Suyasa, dan Marsakawati Analisis Penerjemahan Istilah Budaya pada Novel Negeri 5 Menara ke dalam Bahasa Inggris: Kajian Deskriptif Berorientasi Teori Newmark . Jurnal Ilmu Sosial dan Humaniora

Torop, Peeter. Translation as translating as culture. Department of Semiotics, University of Tartu, Sign Systems Studies 30.2, 2002.

Ye, Hongwei. 2014. On Foreignization of Cultural Elements in the Translation of Classical Chinese Poetry. ISSN 1799-2591. Theory and Practice in Language Studies, Vol. 4, No. 6, pp. 1227-1231, June 2014@ 2014 ACADEMY PUBLISHER Manufactured in Finland. doi:10.4304/tpls.4.6.1227-1231. 
Zare Esmail , Behtash and Firoozkoohi Sepideh. 2009. A Diachronic Study of Domestication and Foreignization Strategies of Culture-Specific Items: in English-Persian Translations of Six of Hemingway's Works. World Applied Sciences Journal 7 (12): 1576-1582, 2009. ISSN 1818-4952 